\title{
Goal-Oriented Training Affects Decision-Making Processes in Virtual and Simulated Fire and Rescue Environments
}

\author{
Sabrina R. Cohen-Hatton \\ Cardiff University; Chief Fire Officers Association, Tamworth \\ Staffordshire; and London Fire Brigade, London, England
}

\author{
R. C. Honey \\ Cardiff University
}

\begin{abstract}
Decisions made by operational commanders at emergency incidents have been characterized as involving a period of information gathering followed by courses of action that are often generated without explicit plan formulation. We examined the efficacy of goal-oriented training in engendering explicit planning that would enable better communication at emergency incidents. While standard training mirrored current operational guidance, goal-oriented training incorporated "decision controls" that highlighted the importance of evaluating goals, anticipated consequences, and risk/benefit analyses once a potential course of action has been identified. In Experiment 1, 3 scenarios (a house fire, road traffic collision, and skip fire) were presented in a virtual environment, and in Experiment 2 they were recreated on the fireground. In Experiment 3, the house fire was recreated as a "live burn," and incident commanders and their crews responded to this scenario as an emergency incident. In all experiments, groups given standard training showed the reported tendency to move directly from information gathering to action, whereas those given goal-oriented training were more likely to develop explicit plans and show anticipatory situational awareness. These results indicate that training can be readily modified to promote explicit plan formulation that could facilitate plan sharing between incident commanders and their teams.
\end{abstract}

Keywords: decision making, situational assessment, plan formulation, decision controls

Understanding decision making in frontline personnel attending emergency incidents is central to the development of operational guidance and increasing safety. Operational models in the United Kingdom emergency services (e.g., Chief Fire and Rescue Advisor, 2008) follow normative analyses of decision making where information gathering precedes the consideration of alternative

This article was published Online First November 2, 2015

Sabrina R. Cohen-Hatton, School of Psychology, Cardiff University; Chief Fire Officers Association, Tamworth, Staffordshire; London Fire Brigade, London, England; R. C. Honey, School of Psychology, Cardiff University.

The research was jointly funded by the Chief Fire Officers Association and the School of Psychology, Cardiff University, and was supported by the Fire Service College and Hampshire Fire and Rescue Service. The authors thank the Chief Fire Officers Association, the Fire Service College and the Fire and Rescue Services and their personnel who took part from: Avon Fire and Rescue Service, Buckinghamshire Fire and Rescue Service, Greater Manchester Fire and Rescue Service, Hampshire Fire and Rescue Service, Hereford and Worcester Fire and Rescue Service, Isle of Wight Fire and Rescue Service, Merseyside Fire and Rescue Service, Northamptonshire Fire and Rescue Service, South Wales Fire and Rescue Service, Tyne and Wear Fire and Rescue Service, West Midlands Fire Service, West Yorkshire Fire and Rescue Service, and Wiltshire Fire and Rescue Service. We also thank Simon Pilling from West Yorkshire Fire and Rescue Service and Andy Bowers from Hampshire Fire and Rescue Service for their assistance and support throughout the project.

Correspondence concerning this article should be addressed to Sabrina R. Cohen-Hatton, School of Psychology, Cardiff University, Tower Building, Park Place, Cardiff CF10 3AT, United Kingdom. E-mail: cohensr@cardiff.ac.uk courses of action and the formulation and execution of a plan (e.g., Dewey, 1933; see also, Lipshitz \& Bar-Ilan, 1996; van den Heuvel, Alison, \& Power, 2014). However, detailed investigation of decision making by operational commanders at emergency incidents indicates that periods of information gathering (i.e., situation assessment) are often followed by the adoption of courses of action (i.e., plan execution) without any apparent mediation by a stage of evaluation or plan formulation. This surprising observation was first highlighted through an analysis of the retrospective reports of incident commanders in North America (Klein, Calderwood, \& MacGregor, 1989; see also, Klein, 1998), but it is also evident in their professional counterparts in the United Kingdom, whose behavior was recently investigated in situ at emergency incidents (Cohen-Hatton, Butler, \& Honey, 2015; see also, Rake \& Njå, 2009).

Cohen-Hatton et al. (2015) examined first-person audio-visual recordings from helmet-mounted cameras (cf. McLennan, Omodei, Rich, \& Wearing, 1997) worn by incident commanders in the United Kingdom Fire and Rescue Service who were attending a sample of 33 incidents, ranging from those involving little threat to human life to major road traffic accidents. The audio-visual record was independently coded as a continuous stream of the relevant categories, namely situation assessment (SA), plan formulation $(\mathrm{PF})$, and plan execution (PE), and the transitions between these categories were then analyzed. Of most interest were the transitions from SA, which were significantly more likely to be to PE than PF (cf. Klein et al., 1989). Moreover, this pattern was evident from the outset of the incidents, when planning might be expected to be most evident. One interpretation of this pattern of results is that decision making in operational contexts often occurs without 
reflective processes of plan formulation, and instead relies on more reflexive processes like recognition-primed decision making (Klein, 1993; see also, Gore, Flin, Stanton, \& Wong, 2015), or associative priming more generally (e.g., Doya, 2008; Honey, 2000), with the situation coming to evoke courses of action through the effects of instruction or direct experience. An alternative interpretation is that plans are reliably formulated and evaluated through reflective processes, but are simply not evident in behavior (Cohen-Hatton et al., 2015) or not recalled (Klein et al., 1989). According to this interpretation, the patterns of transition described by Cohen-Hatton et al. (2015; see also, Klein et al., 1989) were a product of reflective processes that were routinely applied but only inconsistently made explicit.

Whichever interpretation is accurate, it remains the case that information concerning planning can only be communicated effectively with other members of the emergency response teams when it is explicit. In several operational contexts, it has been argued that the development of explicit plans enables shared situational awareness and goals that support a common operating picture (e.g., Endsley, 1995; Schmitt \& Klein, 1999) and interoperability (House, Power, \& Alison, 2014; Stanton, Salmon, \& Walker, 2015). For example, Alison, Power, van den Heuvel, Humann, Palasinski, and Crego (2015) suggest that communication between different agencies (including police, fire, ambulance, and military) attending a simulated disaster is decreased when superordinate goals are lacking. Moreover, at an individual level, a planned course of action that has been assessed with respect to goals, anticipated consequences and an assessment of risk, might provide an incident commander with more confidence to implement that plan, and reduce decision inertia resulting from uncertainty (van de Heuvel, Alison, \& Crego, 2012; see also, Klein, Snowden, \& Pin, 2010).

There are, no doubt, circumstances where reflexive decisions are useful for commanders, particularly in highly dynamic situations where action is required immediately. For example, consider the case of the first responding incident commander at a house fire. The immediate recognition of cues (e.g., indicators that people are in need of rescue; the color and pattern of the smoke) can trigger certain actions that need to be initiated immediately. There are situations, however, when the action triggered by a cue might not be appropriate for the whole incident. To return to the example considered immediately above: The indication that there are people trapped in a building might trigger the commander to commit crews into the building to rescue them immediately, but if considered in conjunction with smoke patterns that suggest a backdraft is imminent, then alternative actions might be needed first, and planning is necessary. A critical issue, therefore, is how best to encourage explicit planning.

The primary aim of our three experiments was assessing whether or not a brief period of goal-oriented training affects the development of explicit plans in experienced incident commanders. To do so, we examined the efficacy of supplementing standard operational training with the use of "decision controls": rapid mental checks concerning goals, anticipated consequences, and an evaluation of risks versus benefits. The goal-oriented training emphasized using these controls when a course of action had been selected, and was intended to ensure that courses of action are routinely evaluated irrespective of whether they have been gener- ated by reflective (see Ajzen, 1991; Dewey, 1933) or reflexive processes (e.g., Doya, 2008; Klein, 1993).

The influence of goal-oriented training was assessed in a variety of scenarios and simulated environments. The three scenarios (a house fire, road traffic collision, and skip fire) were first presented within a fully immersive virtual reality (VR) environment (Experiment 1). Once the effectiveness of goal-oriented training had been established in a VR environment, it was then assessed when the same scenarios were recreated as fire-ground simulations (Experiment 2). Finally, the house fire scenario was recreated as a "live burn" to which the fire crews and incident commanders responded as an emergency incident (Experiment 3). In other respects, the methodology matched that adopted by Cohen-Hatton et al. (2015; see also, McLennan et al., 1997). Thus, the behavior of incident commanders was either video-recorded using a fixed camera in the VR suite (Experiment 1) or recorded from helmet-mounted cameras (Experiments 2 and 3), and the footage was then coded as reflecting $\mathrm{SA}, \mathrm{PF}$, and $\mathrm{PE}$. The transitions between these categories were used to assess whether or not the process of decision making was affected by the nature of training.

Of specific interest in each of the experiments were the transitions between SA and successive categories (i.e., PF and PE), and between PF and either SA or PE, because it was at these transitions where goal-oriented training should have an effect. In particular, we predicted that this training would have a marked influence on the transition from SA to PE, which we assumed was based ordinarily on reflexive processes or a failure to make reflective process explicit; but it would have less of an impact on that from PF to either PE or SA, which we assumed was already controlled by reflective processes. Like Cohen-Hatton et al. (2015), we also assessed situational awareness at the transitions from situational assessment to plan formulation and plan execution. Endsley (1995, 2015) separated situation awareness into three levels: Level 1, involving the perception of elements of the situation; Level 2, relating to the understanding of the situation; and, most relevant to our concerns, Level 3, which involves anticipation of the likely development of the situation. For an operational commander, anticipation of the likely development of the situation can have a critical bearing on safety as it allows the identification of actions necessary for preventing the escalation of the incident, and ensures that any actions taken are considered in the context of the incident. For example, a commander showing Level 2 situation awareness may be focusing on the immediate application of water to a severe fire, and responds directly to the current situation. A commander showing Level 3 situation awareness may consider the likely spread of the fire, predict that the application of water will not be sufficient to restrict the spread, and then create a fire break to prevent the anticipated spread. In Experiments 1-3, assessing anticipation of the likely development of the situation (Level 3 situational awareness) allowed a further index of the efficacy of goal-oriented training.

\section{Experiment 1}

Experiment 1 investigated whether a brief period of goaloriented training affected decision making processes in experienced (Level 1 and Level 2) incident commanders at three simulated incidents: a house fire, road traffic collision, and skip fire. These incidents were presented in an immersive VR environment 
at the Fire Service College (Moreton-in-Marsh, United Kingdom). There were two principal groups: Standard and Decision. Both groups included Level 1 and Level 2 commanders and both received a set of slides accompanied by a test exercise that was designed to reinforce key aspects of the presentations. For Group Standard, the training slides mirrored conventional guidance and during the exercise participants were shown footage of a water rescue incident and at key decision points the footage was paused and participants were asked what action they would take next and why. For Group Decision, slides were included that highlighted the use decision controls, which involved using a rapid mental check list of questions at key decision points: Why am I doing this (i.e., what are my goals)? What do I expect to happen (i.e., what are the anticipated consequences)? and Are the benefits worth the risks? When participants given goal-oriented training watched the footage, and were asked what actions they would take next, they were directed to answer with reference to the decision controls. The two types of training lasted, approximately, $1 \mathrm{hr}$.

Within an hour of the completion of training, all participants received the three fully immersive VR scenarios. Each scenario was displayed on a screen, and both the screen and participants' behavior were recorded by a video camera as the participants engaged in their role as incident commander. This role involved the participants interacting with and directing avatars. Trained assistants in an adjacent room controlled the behavior of the avatars. At predetermined points within the scenarios, participants received standardized "injects" to which they had to respond. Some of these injects involved the avatars (e.g., a distraught parent indicating that their child was trapped in the fire) and others involved events (e.g., the initial deployment of resources at the incident). Eight of these injects were typical of those that might be experienced at that type of incident (e.g., a person being trapped inside the house fire), while the remaining two were less so. For example, one inject involved a rapid rise in temperature, indicating abnormal fire behavior (a flashover) and impending danger to firefighters, at a point where a person remained in need of rescue. This inject results in conflicting goals of firefighter safety and saving life. The latency to respond to these unexpected injects (e.g., by issuing a directive) provided one assessment of whether the differences in training had any general influence on the speed with which incident commanders reacted to incoming information. However, our principal interest was the footage of each scenario, which was independently scored in the way summarized above (e.g., as SA, PF, and PE) and described in detail below. ${ }^{1}$

\section{Method}

Participants. Forty-eight male incident commanders volunteered for this study and provided informed consent for their participation in accordance with local ethical approval through the School of Psychology, Cardiff University. They were drawn from 11 United Kingdom Fire and Rescue Services: Avon Fire and Rescue Service, Buckinghamshire Fire and Rescue Service, Greater Manchester Fire and Rescue Service, Hampshire Fire and Rescue Service, Merseyside Fire and Rescue Service, Northamptonshire Fire and Rescue Service, South Wales Fire and Rescue Service, Tyne and Wear Fire and Rescue Service, West Midlands Fire Service, West Yorkshire Fire and Rescue Service, and Wiltshire Fire and Rescue Service. The sample included Level 1 incident commanders $(N=24)$, usually the first Fire and Rescue staff on scene at an incident, and Level 2 commanders $(N=24)$, who provide command at a higher risk or more complex incidents. The participants were placed in the four groups on the basis of whether they were to receive standard or decision training and were Level 1 or Level 2 commanders. The participants were not informed that there were two types of training. The number of Level 1 and Level 2 commanders in each group was equated, and participants from the same Fire and Rescue Service were evenly distributed across the four groups: Standard/Level 1, Decision/ Level 1, Standard/Level 2, and Decision/Level 2. Previous operational exposure was assessed in a questionnaire that identified how long each participant had spent in operational command positions. The mean overall command experience was 11.97 years $(S E M=0.99 ;$ range $: 0.70-26.50$ years; 7 officers $<5$ years, 13 with 5-10 years inclusive, 15 with $11-15$ years inclusive, 5 with 16-20 inclusive, 6 with $>20$ years). The mean command experience in the current position was 18.00 years $(S E M=.75$; range: $0.50-18.5$ years; 22 officers $<5$ years, 12 with $5-10$ years inclusive, 10 with $11-15$ years inclusive, 2 with $16-20$ inclusive, 0 officers $>20$ years).

Equipment. The participants wore standard issue fire service uniforms. The training presentations were displayed using Prezi on a laptop computer with a 15.2" screen (HP Pavilion, Hewlett Packard). The three scenarios were delivered using incident command simulation software (BlueHawk, The Fire Service College). A high-definition video camera (Handycam HD, Sony) placed on a tripod in the rear right corner of the experimental room $(5 \times 5$ M) simultaneously captured commands from the participants and video footage from a screen $(168 \mathrm{~cm} \times 97 \mathrm{~cm})$ displaying the view of the incident that was being displayed to the participant using the VR goggles (Oculus Rift Development 1, Oculus). Footage was replayed to the participants using a laptop computer (HP Pavilion, Hewlett Packard) on a 15.2" screen, during a cued-recall debrief interview. Each participant's responses during the cued recall interview were recorded using webcams (c270, Logitech). Qualtrics Survey Software was used as a platform to host the incident experience questionnaire, which was delivered on a laptop computer (Alienware 18, Alienware Computers).

Nature of the scenarios. Each participant experienced three scenarios that were representative of fire and rescue service operational activity. Role players were used for each avatar that interacted with the incident commander. All scenarios were scripted, with 10 injects per scenario. Each role player had a script containing the information that their character had at their disposal. Any other information that participants requested that was not included in the script was to be answered with "I don't know." The three scenarios are summarized below.

1. House fire. Participants were confronted with fire in a domestic property and a distraught parent indicating their child was trapped inside the burning house. This is a typical incident that Level 1 or Level 2 commanders could expect to command, and represents a dynamic situation where action is urgently required,

\footnotetext{
${ }^{1}$ This footage was also replayed to the participants, which enabled the resulting transcripts of their commentary to provide converging evidence on the few occasions when independent coding had revealed an ambiguity in the categorization of the activity.
} 
and there is a high risk to both firefighters and to the missing child. An example of a standard inject was the arrival of a second fire crew, and of an unexpected event was the receipt of information to suggest that the child was in a location other than the one last reported. The interval between the 10 injects was, on average, 1-2 min, and there were five main avatars that interacted.

2. Road traffic collision. A car had been involved in a road traffic collision with another vehicle. One person was trapped because of the nature of their injuries, suffering from neck and back pain as a result of the collision. The car later transpired to be an undercover police car, with covert video cameras making standard extrication techniques difficult. This incident has a high risk to life, as there is a trapped casualty, but time pressure is low, allowing the commander time to consider their course of action. An example of a standard inject was the arrival of a second fire crew, and of an unexpected event was the failure of a critical piece of equipment. The interval between the 10 injects was, on average, $2 \mathrm{~min}$, and there were five main avatars that interacted with the participant.

3. Skip fire spreading to adjoining shop. Participants were initially alerted to a shop fire, although on arrival it transpired that there was a fire in a skip in the yard behind the shop, which later spreads to the shop. There are a number of considerations: the difficulty in gaining access to the site, the fire not extinguishing in the way expected given the information provided on the contents of the skip, and a number of residential flats in the adjoining properties that might be affected. An example of a standard inject was the arrival of a second fire crew, and an unexpected inject was the failure of the water supply. The interval between the 10 injects was, on average, 1-2 min, and there were four main avatars that interacted with the participant.

Procedure. Each participant was briefed on the procedure and gave informed consent for their participation. Participants were randomly assigned to either Group Standard or Group Decision, with an equal allocation of Level 1 and Level 2 commanders to each group. Two participants suffered motion sickness during the VR scenarios, and the final number of participants was 46. Participants either received the Standard or Decision training presen- tations displayed using Prezi, and their responses to an exercise embedded within it were recorded using a webcam. The two types of training were presented in standardized format, and the practical exercise used to reinforce the training was based upon video footage of an incident that required the fire and rescue service to perform a water rescue, where a car was trapped in swollen floodwater. The video was presented as a series of 11 clips (approximate durations $=1 \mathrm{~min}$.). After each clip, the participants were invited to describe what their actions would be as the incident commander of this incident. Those given Standard training were asked to command as they would presently, using current accepted practices and were asked to verbalize what they would do next and why. In contrast, Decision training involved the participants providing a brief explanation of the questions that should be asked before a course of action was executed. In particular, three questions were emphasized: Why am I doing this (i.e., what are my goals)? What do I expect to happen (i.e., what are the anticipated consequences)? Are the benefits worth the risks? After each clip, participants were also asked to verbalize what they would do next, with reference to these three questions. In neither group were the participants given feedback regarding their responses. The two forms of training took, approximately, $60 \mathrm{~min}$.

Once training was complete, the participants were taken to the VR suite where they took part in each of the three scenarios. The scenarios were presented in a counterbalanced order within each group. Immediately after each scenario, participants were given a cued recall debrief. This involved them reviewing the video footage taken from the video cameras. They were asked to recall their thoughts and rationale for various decisions at the time the footage was taken. All footage was stored securely on a drive encrypted with TrueCrypt software (TrueCrypt version 5.1, TrueCrypt Foundation).

\section{Results}

Coding of activity. Table 1 defines the three primary categories (SA, PF, and PE) alongside specific examples of each category taken from Experiment 1 . These independently coded categories of activity represent the primary data, and interrater reliability checks

Table 1

Coding Dictionary

\begin{tabular}{|c|c|c|c|}
\hline Decision phase & Incident command model definition & Description & Example \\
\hline Situation assessment (SA) & $\begin{array}{l}\text { Gathering incident, resource, or hazard } \\
\text { information. }\end{array}$ & $\begin{array}{l}\text { Acknowledgement of information } \\
\text { relating to the environment, } \\
\text { surveying scene. }\end{array}$ & "There's smoke issuing." \\
\hline Plan formulation $(\mathrm{PF})$ & $\begin{array}{l}\text { Identification and prioritizing objectives, } \\
\text { developing tactical plan. }\end{array}$ & $\begin{array}{l}\text { Problem identification, ordering } \\
\text { of tasks, planning activities, } \\
\text { consideration of rationale. }\end{array}$ & $\begin{array}{l}\text { "We need to stop fire spread... } \\
\text { [you] put water in there... } \\
\text { [team 2]monitor downstairs to } \\
\text { check for fire spread..." }\end{array}$ \\
\hline Plan execution (PE) & $\begin{array}{l}\text { Communicating actions and controlling } \\
\text { activity. }\end{array}$ & $\begin{array}{l}\text { Communication of tasks, } \\
\text { controlling progress of tasks, } \\
\text { setting tempo, changing } \\
\text { activities. }\end{array}$ & $\begin{array}{l}\text { "I want you to search the first } \\
\text { floor, taking a hose reel. .." }\end{array}$ \\
\hline \multirow[t]{2}{*}{ Level 3 situation awareness } & Anticipation. & $\begin{array}{l}\text { Evidence of predicting the likely } \\
\text { outcomes of actions, or the } \\
\text { likely development of the } \\
\text { situation. }\end{array}$ & $\begin{array}{l}\text { "I'm thinking of going Tactical } \\
\text { Vent level 3, if I don't have an } \\
\text { exit port it will get worse... }\end{array}$ \\
\hline & & & $\begin{array}{l}\text { "I think that fire is going to } \\
\text { spread next door..." }\end{array}$ \\
\hline
\end{tabular}


revealed that the sequences of state transitions were highly reliable across the two coders (SC-H and $\mathrm{RCH}$ ). Thus, randomly chosen excerpts of video footage (one from each of the three scenarios; see below) were scored by both coders and there was $>95 \%$ agreement between the sequences of state transitions that were generated. Very occasionally the transcripts from the cued-recall interview were used to clarify interpretation of a transition. Evidence of Level 3 situational awareness (anticipation of how the situation might unfold) was coded at the transitions from SA (Endsley, 1995; cf. Cohen-Hatton et al., 2015). Again, the agreement between coders was high $>90 \%$.

Occasions when decision controls were explicitly used were coded in terms of evidence of the explicit consideration of (a) goals or rationale, (b) identifying expectations, and (c) consideration of the benefits versus the risks of a potential course of action. Finally, the latency to respond to the unexpected injects (e.g., by issuing a directive) was measured to provide an index of whether or not the different forms of training resulted in changes in the speed with which participants responded to components of the incident.

Data analysis. A lag sequential analysis characterized how the categories of activity changed over the course of the three scenarios. This analysis produces a sequence of transitions from which the conditional probabilities that SA would be followed by PF (or PE), and PF by PE (or SA) were derived (Sackett, 1979; see also, O'Connor, 1999). The analysis starts with the definition of a criterion position for each participant, which in this case was the first inject, and thereafter activity coded as SA, PF, and PE was used to generate a lag sequence of the transitions between the different categories. The lag sequence removes immediate repetition of the same category to provide a trace of the category transitions; for example, the raw sequence SA, SA, SA, PE, PE, PF, PF, PF SA, PE becomes SA, PE, PF, SA, PE. The analysis terminates with the end of the scenario. From the resulting traces, the mean overall conditional probability that one category would be followed by another was calculated (i.e., SA to PE or PF; PF to PE or SA; PE to SA or PF). A mean conditional probability of 0.50 for transitions from SA (to $\mathrm{PF}$ ) indicates that transitions from SA were equally likely to be to PF as to PE. The statistical analysis focused on the conditional probabilities of the transitions from SA to $\mathrm{PE}, \mathrm{PF}$ to $\mathrm{PE}$, and $\mathrm{PE}$ to $\mathrm{SA}$ (that can each take a value between 0 and 1); with the transitions from $\mathrm{SA}$ to $\mathrm{PF}, \mathrm{PF}$ to $\mathrm{SA}$, and $\mathrm{PE}$ to PF simply reflecting the reciprocal values.

Lag sequential analysis. Figure 1 depicts the mean conditional probabilities for the transitions from SA to either PF or PE (upper panels), from PF to either PE or SA (middle panels), and from PE to either SA or PF (lower panels). The results were pooled across whether the participants were Level 1 or Level 2 incident commanders and the three scenarios, because statistical analyses revealed that these factors had no independent effect and did not interact with other factors (all $F \mathrm{~s}<1$ ). The pattern of transitions from SA for Group Standard was similar to that observed by Cohen-Hatton et al. (2015) for real incidents attended by the fire and rescue service: SA was more likely to be followed by PE than PF. In contrast, for participants in Group Decision, SA was more likely to be followed by PF than PE. An independent-samples $t$ test conducted on the probabilities of transition from SA to PE confirmed that the groups differed, $t(44)=5.36, p<.001, d=1.62$; and one-sample $t$ tests showed that the SA-PE transition was more likely than would be expected on the basis of chance (0.50) in Group Standard, $t(21)=4.51, p<.001, d=0.96$, whereas the SA-PF transition was more likely than would be expected on the basis of chance (.50) in Group Decision, $t(23)=2.91, p<.01$, $d=0.59$. Moving on to the transitions from $\mathrm{PF}$, inspection of the center panels indicates that the PF-PE transition was more likely than the PF-SA transition in both groups. An independent-samples $t$ test confirmed that the groups did not differ, $t(44)=1.56, p>$ $.12, d=0.47$; and one-sample $t$ tests showed that the PF-PE transition was more likely than would be expected on the basis of chance (0.50) in both Group Standard, $t(21)=6.34, p<.001, d=$ 1.35 , and Group Decision, $t(23)=12.75, p<.001, d=2.60$. For this transition, Cohen-Hatton et al. (2015) observed that the PF-PE and PF-SA transitions were equiprobable. Finally, the lower panel illustrates the probabilities of transition from PE to SA and PF. Inspection of this panel reveals that PE was more likely to be followed by SA than PF in both groups. An independent-samples $t$ test confirmed that there was no significant difference between the groups, $t(44)=0.31, p>0.75, d=0.09$; and one-sample $t$ tests confirmed that the PE-SA transition was more likely than would be expected on the basis chance (0.50) in Group Standard, $t(21)=22.46, p<.001, d=4.79$, and Group Decision, $t(23)=$ 23.06, $p<.001, d=4.71$ (matching the results reported by Cohen-Hatton et al., 2015).

Situation awareness. Over the course of the incidents, there was more Level 3 SA (anticipation) at the SA transitions in Group Decision $(M=11.79, S E M=1.36)$ than in Group Standard $(M=$ 4.95, $S E M=0.97), t(44)=4.01, p<.001, d=1.21$. The overall frequency of transitions from $\mathrm{SA}$ (to $\mathrm{PF}$ or $\mathrm{PE}$ ) did not differ between Groups Standard $(M=40.32, S E M=0.75)$ and Decision $(M=41.46, S E M=0.77), t(44)=1.06, p>.29, d=0.32$.

Manipulation checks. The frequency with which participants mentioned decision controls was greater in Group Decision than in Group Standard. Analysis of variance (ANOVA) with group and decision control (goals, expectations, and benefits/risks) as factors, revealed a main effect group, $F(1,44)=27.47, p<.001, \eta_{\mathrm{p}}^{2}=$ 0.38 , decision control, $F(2,88)=67.45, p<.001, \eta_{\mathrm{p}}^{2}=0.60$, and an interaction between these two factors $F(2,84)=9.02, p<.001$, $\eta_{\mathrm{p}}^{2}=0.17$. Independent-samples $t$ tests showed that Group Decision was more likely than Group Standard to mention goals (Decision: $M=16.29$, SEM $=1.17$; Standard: $M=7.73$, $S E M=$ $0.81), t(44)=5.91, p<.001, d=1.78$, and expected outcomes (Decision: $M=8.88, S E M=1.62$; Standard: $M=3.27$, $S E M=$ $0.81), t(44)=2.99, p<.005, d=0.90$. Although the frequency with which benefits/risks were mentioned was numerically higher in Group Decision $(M=2.42, S E M=0.44)$ than in Group Standard $(M=1.27, S E M=0.39)$, this difference failed to reach conventional levels of statistical significance, $t(44)=1.95, p=$ $.058, d=0.59$. Finally, the latency to respond to the unexpected injects did not differ between the groups (Standard: $M=5.73 \mathrm{~s}$, $S E M=1.37$; Decision: $M=4.45 \mathrm{~s}, S E M=.67, t(44)=0.86 . p>$ $.39, d=0.26)$.

\section{Discussion}

Experiment 1 investigated whether the decision making activity of experienced incident commanders in the fire and rescue service could be modified by the nature of the training that they had received before commanding incidents within three VR scenarios. 


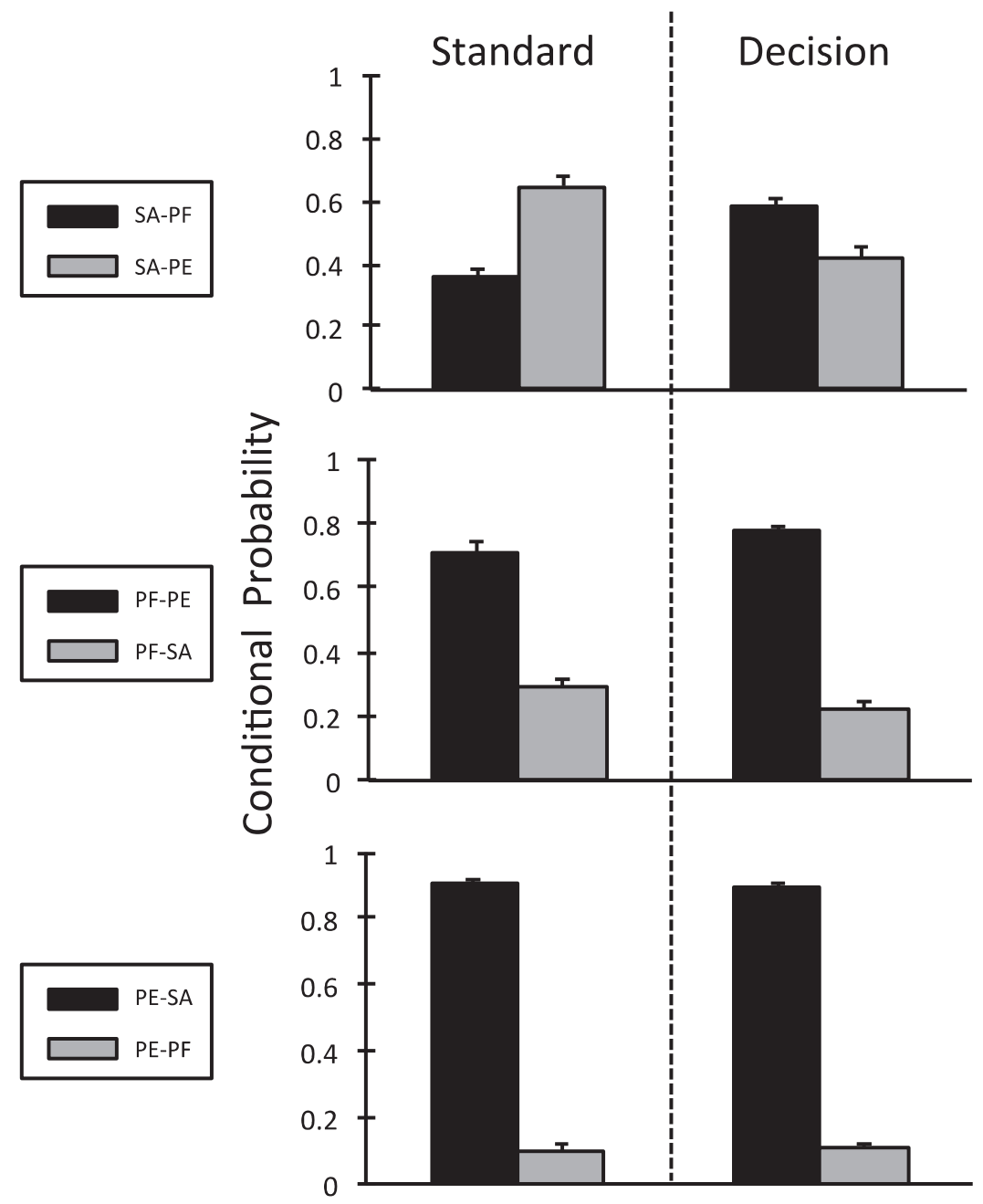

Figure 1. Experiment 1: Immersive VR incidents (a house fire, road traffic collision, and skip fire). Mean ( $+S E M)$ conditional probabilities of transition from situation assessment (to PF or PE; upper panel); from plan formulation (to PE or SA; center panel); and from plan execution (to SA or PF; lower panel). The scores for Groups Standard and Decision are pooled across the three types of incident and the level of the incident commander (Level 1 or 2). VR = virtual reality; $\mathrm{SA}=$ situation assessment; $\mathrm{PE}=$ plan execution; $\mathrm{PF}=$ plan formation.

Training either followed the standard model of operation guidance that incident commanders would routinely experience (Group Standard) or it was goal-oriented, emphasizing goal evaluation, anticipated outcomes, and risk/benefit analyses before the execution of a potential course of action (Group Decision). The activity of incident commanders was coded as SA, PF, and PE, and the pattern of transitions between these categories was examined. In Group Standard, the pattern of transitions was similar to those observed at emergency incidents (Cohen-Hatton et al., 2015), and echoed qualitative observations (Rake \& Njå, 2009) and retrospective reports (Klein et al., 1989; see also, Klein, 1998). Critically, SA was more likely to be followed by PE than PF. However, this failure to exhibit planful behavior was much less apparent in Group Decision, where SA was more likely to be followed by PF than PE. This difference in transitions was accompanied by differences in the frequency with which decision controls were men- tioned throughout the incidents. The marked difference in the pattern of transitions from SA was not accompanied by differences in the transitions from PF, which were more likely to be to PE in both groups, or PE, which was more likely to be to SA in both groups. Moreover, the difference in training had no significant impact on the latency to respond to a sample of injects (i.e., those involving unexpected events).

The fact that the pattern of transitions for participants in Group Standard were similar to those observed at real incidents by Cohen-Hatton et al. (2015) provides direct support for the suggestion that the scenarios and VR environment engender incident commander activity that mirrors that seen at real incidents. This observation suggests that the changes in decision-making processes following goal-oriented training would also be seen if incident commanders were faced with real operational incidents. However, unlike during real incidents, participants in the VR 
scenarios were more likely to execute decisions having formulated a plan as opposed to reassessing the situation. This difference suggests that one should be cautious before generalizing the results of Experiment 1 to real operational incidents. In particular, the influence of goal-oriented training on the likelihood that incident commanders formulate plans once they have assessed the situation, needs to be investigated when our scenarios are embedded in more realistic environments. This was the principal aim of Experiments 2 and 3.

\section{Experiment 2}

Experiment 2 investigated the impact of goal-oriented training on incident commanders who were engaged in the same set of scenarios as Experiment 1, but that were now recreated on the fire ground at the Fire Service College (Moreton-in-Marsh, United Kingdom). These simulations, including the injects, closely matched the three scenarios from Experiment 1. In Experiment 2, however, standard fire service equipment (e.g., a fire engine) and resources were used, and fire crews were present. The crews were blind to the nature of training that the incident commanders had received. Helmet-mounted cameras were used to record firstperson footage of the activity of incident commanders (cf. CohenHatton et al., 2015; see also, Roberts, Flin, \& Cleland, 2015).

\section{Method}

Participants. Ten male Level 1 incident commanders volunteered for this study. The smaller number of participants in this experiment, relative to Experiment 1, reflects the facts that (a) each incident represents a considerable investment of resources, and (b) the training had marked effects in Experiment 1. The participants provided informed consent for their participation in accordance with local ethical approval through the School of Psychology, Cardiff University. They were drawn from 6 United Kingdom Fire and Rescue Services: Hampshire Fire and Rescue Service, South Wales Fire and Rescue Service, Tyne and Wear Fire and Rescue Service, Hereford and Worcester Fire and Rescue Service, West Midlands Fire Service, and West Yorkshire Fire and Rescue Service. The participants were randomly assigned to the two groups, Standard and Decision. A questionnaire was used to identify how long each participant had spent in operational command positions. The mean overall command experience of the Level 1 commanders was 10.2 years $(S E M=2.12$; range: $0.40-22.00$ years; 2 officers with $<5$ years, 4 with $5-10$ years inclusive, 1 with $11-15$ years inclusive, 2 with $16-20$ inclusive, 1 with $>20$ years).

Equipment. Participants arrived at the incidents in a standard fire engine, which carried equipment including a $13.5 \mathrm{~m}$ ladder, a pump, 1,800 liters of water, breathing apparatus, and road traffic collision rescue equipment. The fire engine was crewed by five firefighters who were not informed about the training that the incident commanders had been given. The participants wore standard issue fire service uniforms supplemented by helmet-mounted 1,080 p high-definition video cameras, measuring $42 \times 60 \times 30$ $\mathrm{mm}$ (GoPro Hero 3, Half Moon Bay). The footage was replayed to participants on a laptop computer (HP Pavilion, Hewlett Packard), on a 15.2" screen during a cued-recall debrief interview.

Procedure. The three scenarios matched those used in Experiment 1 . The same characters, injects, and timings were used. The main differences were that the characters were real as opposed to avatars and the commanders could interact directly and more naturally with crews. As in Experiment 1, each participant was briefed on the procedure, gave informed consent for their participation, and were randomly assigned to either Group Standard or Group Decision. Initially, 12 commanders were because of participate. However, 2 commanders were unable to complete all scenarios so their data sets were excluded and the final number of participants was 10. Participants either experienced the Standard or Decision training in accordance with the procedure adopted in Experiment 1. They were then taken to the Fire Service College training ground where they took part in each scenario. The order in which the participants received the scenarios was counterbalanced in the same way for both groups. Commanders were mobilized from a fire engine, receiving instructions on the nature and location of the call, which mirrored normal practice. Immediately after each scenario, participants received a cued recall debrief in the same way as in Experiment 1. Other details of the procedure that have not been mentioned were the same as in Experiment 1 .

\section{Results and Discussion}

Lag sequential analysis. Figure 2 shows the mean conditional probabilities for the three types of transition: from SA to either PF or PE (upper panels), from PF to either PE or SA (middle panels), and from PE to either SA or PF (lower panels). As in Experiment 1, these probabilities were pooled across the three different scenarios. Inspection of the upper panel of this figure shows that participants in Group Standard behaved in a similar way to those in the equivalent group in Experiment 1, and to incident commanders attending real incidents (Cohen-Hatton et al., 2015): SA was more likely to be followed by PE than PF. However, and as in Experiment 1, this bias was markedly reduced, if not reversed on this occasion, in Group Decision. An independent samples $t$ test conducted on the conditional probabilities for the SA-PE transition confirmed that the groups differed, $t(8)=3.99$, $p<.005, d=2.82$; and one-sample $t$ tests showed that the SA-PE transition was more likely than would be expected on the basis of chance (0.50) in Group Standard, $t(4)=5.19, p<.01, d=2.32$, but this was not the case in Group Decision, $t(4)=0.13, p>.90$, $d=0.06$. The transitions from PF were more likely to be to PE than SA in both groups. An independent-samples $t$ test confirmed that there was no significant effect of group, $t(8)=0.31, p>.76$, $d=0.22$; and one-sample $t$ tests showed that the PF-PE transition was more likely than would be expected on the basis of chance $(0.50)$ in both Groups Standard, $t(4)=9.63, p<.005, d=4.30$, and Decision, $t(4)=6.74, p<.005, d=3.01$. There was no group difference in the PE-SA conditional probabilities, $t(8)=0.26, p>$ $.79, d=0.18$; and one-sample $t$ tests showed that the PE-SA transition was more likely than would be expected on the basis of chance (0.50) in both Groups Standard, $t(4)=107.90, p<.001$, $d=48.25$, and Decision, $t(4)=70.17, p<.001, d=31.38$.

Situation awareness. Over the course of the incidents, although numerically there was more Level 3 SA (anticipation) at the SA transitions in Group Decision $(M=4.80, S E M=1.65)$ than in Group Standard $(M=3.20, S E M=0.37)$, this difference was not statistically significant, $t(8)=0.94, p>.37, d=0.66$. This difference might either reflect the nature of the simulations or the fact that there was a smaller number of participants in Exper- 


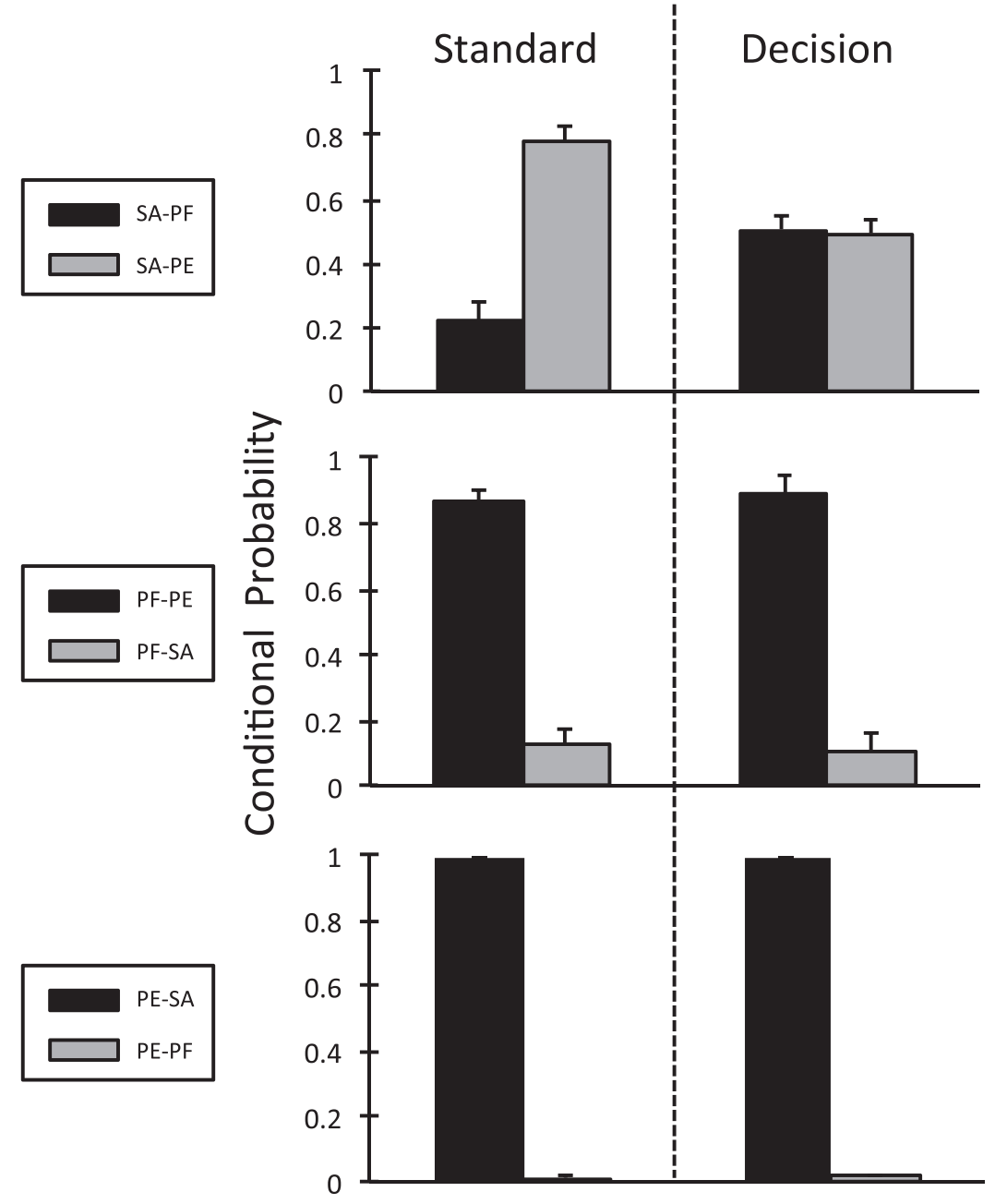

Figure 2. Experiment 2: Fire-ground recreations of VR incidents (a house fire, road traffic collision, and skip fire). Mean ( $+S E M)$ conditional probabilities of transition from situation assessment (to PF or PE; upper panel); from plan formulation (to PE or SA; center panel); and from plan execution (to SA or PF; lower panel). The scores for Groups Standard and Decision are pooled across the three types of incident scenarios. All participants were Level 1 incident commanders. $\mathrm{VR}=$ virtual reality; $\mathrm{SA}=$ situation assessment; $\mathrm{PE}=$ plan execution; $\mathrm{PF}=$ plan formation.

iment 2 than in Experiment 1. The overall frequency of transitions from SA did not differ significantly between Groups Standard $(M=55.80, S E M=3.61)$ and Decision $(M=45.00, S E M=$ 3.18), $t(8)=2.24, p>.05, d=1.58$.

Manipulation checks. The frequency with which participants mentioned decision controls (specifically goals and expected outcomes) was greater in Group Decision than in Group Standard. ANOVA revealed an effect of group, $F(1,8)=22.70, p<.001$, $\eta_{\mathrm{p}}^{2}=0.74$, decision control (i.e., goals, expectations, and benefits/ risks), $F(2,16)=98.58, p<.001, \eta_{\mathrm{p}}^{2}=0.92$, and an interaction between these two factors, $F(2,16)=20.40, p<.001$, $\eta_{\mathrm{p}}^{2}=0.72$. Independent-samples $t$ tests showed that Group Decision were more likely than Group Standard to mention both goals (Group Decision: $M=24.40, S E M=1.81$ : Group Standard: $M=9.60$, $S E M=1.96), t(8)=5.55, p<.01, d=3.92$, and expected outcomes (Group Decision: $M=5.60, S E M=1.60$; Group Standard: $M=1.60, S E M=0.24), t(8)=2.47, p<.05, d=1.75$.
There was no statistical difference between the frequency with which the groups mentioned benefits/risks (Decision: $M=2.20$, $S E M=0.58$; Standard: $M=1.80, S E M=0.58), t(8)=0.37, p=$ $.72, d=0.26$. Finally, the latency to respond to the unexpected injects did not differ between Groups Standard $(M=2.59 \mathrm{~s}$, $S E M=0.58)$ and Decision $(M=1.76 \mathrm{~s}, S E M=0.22), t(8)=1.35$, $p>.21, d=0.95$.

\section{Experiment 3}

In Experiment 3 we assessed the impact of goal-oriented training on the decision-making activity of Levels 1 and 2 commanders who were attending a "live burn" that recreated the house fire scenario from Experiments 1 and 2. The live burn involved setting fire to a building that had previously served as accommodation. The characters, injects and timings matched, as closely as possible, those from the equivalent scenario in Experiments 1 and 2. 


\section{Method}

Participants. Twenty-four male incident commanders volunteered for this study and provided informed consent for their participation in accordance with local ethical approval through the School of Psychology, Cardiff University. They were drawn from two United Kingdom Fire and Rescue Services: Hampshire Fire and Rescue Service, and Isle of Wight Fire and Rescue Service. As in Experiment 1, the sample included Level 1 incident commanders $(N=12)$ and Level 2 commanders $(N=12)$ who were placed in four groups (i.e., Standard/Level 1, Decision/Level 1, Standard/ Level 2, Decision/Level 2), with the commanders from the two Fire and Rescue Services evenly distributed across the four groups. The mean overall command experience was 9.61 years $(S E M=$ 0.89 ; range: $1.00-15.30$ years; 4 officers $<5$ years, 16 with $5-10$ years inclusive, 4 with $11-15$ years inclusive, 0 with16-20 inclusive, 0 with $>20$ years). The mean command experience in the current position was 6.84 years $(S E M=0.88$; range $: 1.00-17.00$ years; 10 officers with $<5$ years, 10 with $5-10$ years inclusive, 3 with 11-15 years inclusive, 1 with 16-20 inclusive, 0 officers $>20$ years).

Equipment. Participants arrived at the incidents in either a standard fire engine similar to that described in Experiment 2 (Level 1 Commanders) or their own fire response cars (Level 2 Commanders), and wore standard issue fire service uniforms again supplemented with a helmet-mounted 1,080 p high-definition video cameras (GoPro Hero 3, Half Moon Bay). The footage was replayed to participants on a laptop computer (HP Pavilion, Hewlett Packard), on a 15.2" screen during a cued-recall debrief interview.

Scenario and procedure. The house fire scenario matched that used in Experiments 1 and 2, with the same characters, injects, and timings. The principal difference between Experiment 3 and Experiment 2 was that the scenario now involved fire. As in Experiments 1 and 2, each participant was briefed on the procedure, gave informed consent for their participation, and were randomly assigned to either Group Standard or Group Decision and received their designated training in the same way as Experiment 1 . They were then mobilized from a fire engine that was about .5 miles from the incident, where they received instructions on the nature and location of the call, which mirrored normal practice. The characters and crews were not informed about the training give to the incident commanders. As in Experiments 1 and 2 , immediately after each scenario, participants took part in a cued-recall debrief. Other details of the procedure that have not been mentioned were the same as in Experiments 1 and 2.

\section{Results and Discussion}

Lag sequential analysis. Figure 3 depicts the mean conditional probabilities for the three types of transition: from SA to either PF or PE (upper panels), from PF to either PE or SA (middle panels), and from PE to either SA or PF (lower panels). The results were pooled across whether the participants were Levels 1 or 2 incident commanders, because statistical analyses revealed that this factor had no independent effect and did not interact with group $\left(F_{\mathrm{S}}<1\right)$. As in Experiments 1 and 2, the SA-PE transitional probabilities differed between Groups Standard and Decision, $t(22)=4.38, p<.001, d=1.87$; and one-sample $t$ tests confirmed that the SA-PE transition was more likely than would be expected on the basis of chance (0.50) in Group Standard, $t(11)=4.29, p<$ $.005, d=1.24$, whereas this bias was markedly reduced if not significantly reversed in Group Decision, $t(11)=1.56, p>.14$, $d=0.45$. In both groups, the PF-PE transition was more likely than the PF-SA transition, and there was some indication that this pattern was especially marked in Group Decision. ${ }^{2}$ An independent-samples $t$ test confirmed that the groups differed, $t(22)=2.23, p<.05, d=0.95$, and one-sample $t$ tests showed that the PF-PE transition was more likely than would be expected on the basis of chance (0.50) in both Group Standard, $t(11)=2.71$, $p<.05, d=0.78$, and in Group Decision, $t(11)=12.67, p<.001$, $d=3.66$. Finally, analysis of the PE-SA transition confirmed that the groups did not differ, $t(22)=1.59, p>.12, d=0.68$; and one-sample $t$ tests confirmed that the PE-SA transition was more likely than would be expected on the basis of chance (.50) in Groups Standard, $t(11)=23.46, p<.001, d=6.77$, and Decision, $t(11)=60.56, p<.001, d=17.48$.

Situation awareness. Over the course of the incidents, there was more Level 3 situation awareness (anticipation) at the SA transitions in Group Decision $(M=4.92, S E M=0.94)$ than in Group Standard $(M=0.92, S E M=0.34), t(22)=4.00, p<.01$, $d=1.72$. The overall frequency of transitions from SA did not differ between the groups (Standard: $M=18.00, S E M=1.54$; Decision: $M=18.67, S E M=1.10), t(22)=0.35, p>.72, d=$ 0.15 .

Manipulation checks. Participants in Group Decision were more likely to mention decision controls than those in Group Standard. ANOVA revealed an effect of group, $F(1,22)=41.39$, $p<.001, \eta_{\mathrm{p}}^{2}=0.65$, decision control, $F(2,44)=71.39, p<.001$, $\eta_{\mathrm{p}}^{2}=0.76$, and an interaction between these factors $F(2,44)=$ $4.39, p<.05, \eta_{\mathrm{p}}^{2}=0.17$. Independent-samples $t$ tests revealed that Group Decision were more likely than Group Standard to mention goals (Decision: $M=8.75$, SEM $=0.74$; Standard: $M=4.58$, $S E M=0.56), t(22)=4.62, p<.001, d=1.97$, expected consequences (Decision: $M=4.17, S E M=0.34$; Standard: $M=$ 1.42, SEM $=0.40), t(22)=5.22, p<.001, d=2.23$, and benefits/risks (Decision: $M=2.25, S E M=0.49$; Standard: $M=$ $0.75, S E M=0.22), t(22)=2.78, p<.05, d=1.18$. Finally, the latency to respond to unexpected injects did not differ between Group Standard $(M=1.50 \mathrm{~s}, S E M=0.23)$ and Group Decision $(M=2.67 \mathrm{~s}, S E M=.0 .65), t(22)=1.70, p>.10, d=0.72$.

\section{General Discussion}

Converging evidence suggests that incident commanders from the fire and rescue services, who are prosecuting their roles at emergency incidents, frequently initiate actions without making explicit plans (e.g., Cohen-Hatton et al., 2015; Klein et al., 1989; Rake \& Njå, 2009). This practice might reflect either a reliance on reflexive processes or a failure to make explicit, plans formulated and evaluated through reflective processes. It has been argued that promoting the development of explicit plans enables shared situational awareness and goals to support a common operating picture (e.g., Endsley, 1995; Schmitt \& Klein, 1999), and facilitates interoperability (Alison et al., 2015; House et al., 2014; Stanton et

\footnotetext{
${ }^{2}$ The conditional probabilities for PF-PE and PF-SA do not sum to one in Group Standard because for one participant there were no instances of plan formulation (i.e., both conditional probabilities were zero).
} 


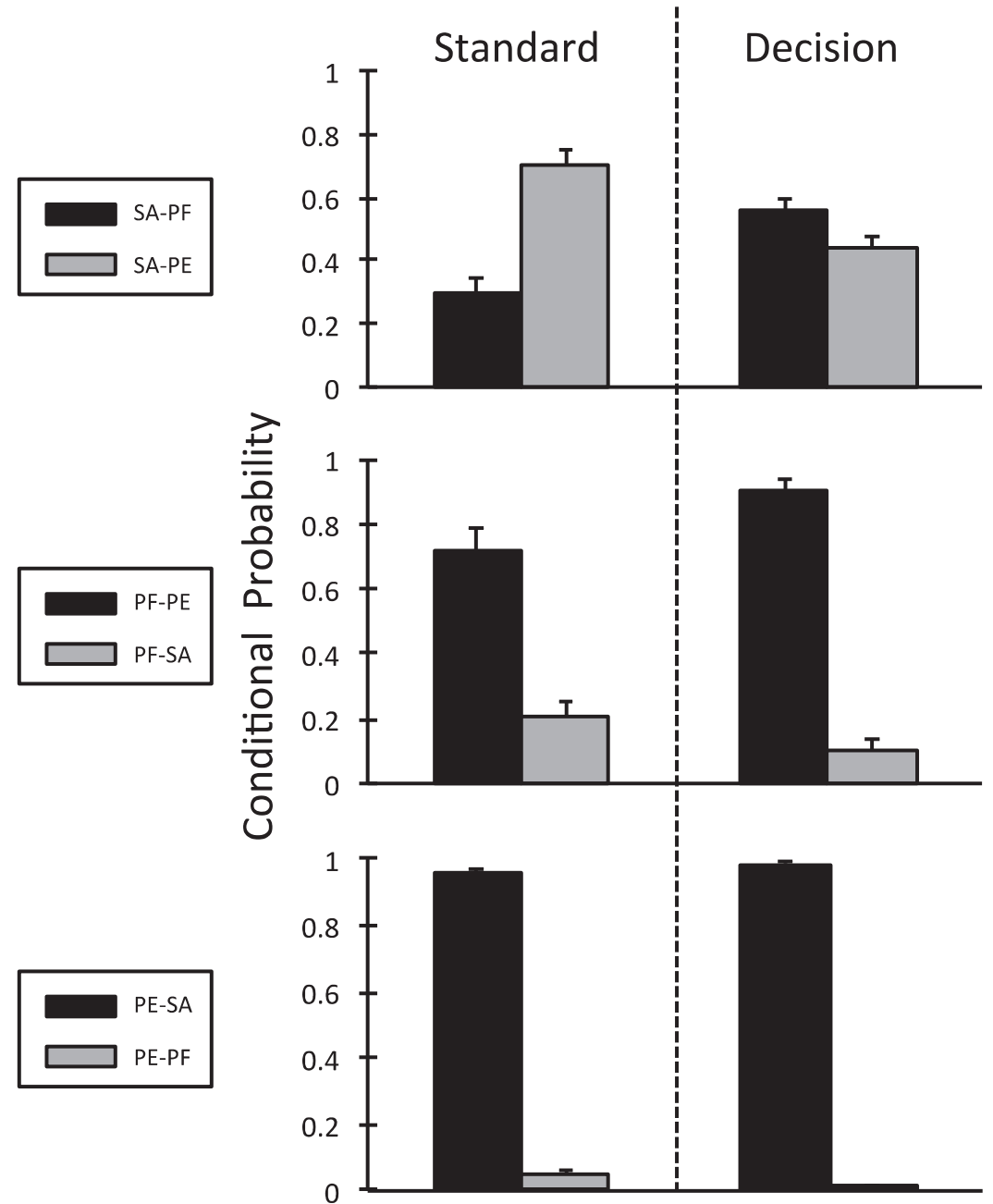

Figure 3. Experiment 3: Live house fire. Mean $(+S E M)$ conditional probabilities of transition from situation assessment (to PF or PE; upper panel); from plan formulation (PE or SA; middle panel); and from plan execution (to SA or PF; lower panel). The scores for Groups Standard and Decision and are pooled across the level of the incident commander (Level 1 or 2 ). $\mathrm{SA}=$ situation assessment; $\mathrm{PE}=$ plan execution; $\mathrm{PF}=$ plan formation.

al., 2015). Here, we assessed whether explicit plan formulation could be promoted through training that encouraged experienced incident commanders, within the United Kingdom Fire and Rescue Service, to consider three questions before initiating actions: Why am I doing this (i.e., what are my goals)? What do I expect to happen (i.e., what are the anticipated consequences)? Are the benefits worth the risks? That is, we assessed the effect of goaloriented training on decision-making processes. The three experiments used a range of scenarios (a house fire, road traffic collision, and skip fire) that were either presented within a fully immersive VR environment (Experiment 1), recreated on the fireground (Experiment 2) or as a "live burn" to which the fire crews and incident commanders responded as an emergency incident (Experiment 3). The activity of incident commanders was recorded and then categorized as reflecting SA, PF, and PE (see Table 1; Cohen-Hatton et al., 2015; see also, McLennan et al., 1997). The results of the experiments provided consistent support for a number of conclusions concerning the way in which goal-oriented training affected the command of the simulated incidents and the utility of the simulated exercises more broadly.

The principal observation that motivated the current research was that SA is more likely to be followed by PE than PF in incident commanders attending live incidents (e.g., Cohen-Hatton et al., 2015) and in those recalling their experiences in the field (Klein et al., 1989; see also, Rake \& Njå, 2009). In Experiments $1-3$, experienced incident commanders given standard training exhibited this pattern of transitions in all three simulated environments (involving VR, fire ground, and live burns). This observation confirmed that our simulated environments generate patterns of activity that mirror those observed at a range of live incidents (Cohen-Hatton et al., 2015), and provide an effective baseline against which to assess the efficacy of goal-oriented training: The primary objective of the three experiments. In each experiment, goal-oriented training, involving encouraging the use of decision controls (considering goals, consequences, and an analysis of risk), affected whether the transition from situation awareness was to 
plan formulation or plan execution: Incident commanders given goal-oriented training were more likely to show plan formulation (and less likely to show plan execution) after situation assessment than those given standard training. This change in the transitions from SA was accompanied by an increase in the overall tendency for participants to give explicit consideration to goals and anticipated consequences, and increased anticipatory situation awareness. Moreover these changes occurred without increases in the latency to respond to unexpected injects within the three simulated environments. The latter finding suggests that training in the use of decision controls did not result in a general reduction in the capacity of participants to respond quickly to unfolding events.

The influence of goal-oriented training on conditional transition probabilities from SA, PF and PE was restricted to the transitions from SA. The transition from SA to PE was originally targeted given the assumption that this transition was based on reflexive processes that were not mediated by reflective planful processes (Cohen-Hatton et al., 2015; see also, Klein et al., 1989; Rake \& Njå, 2009). It was assumed that those transitions from PF to PE (or SA) were under the control of reflective processes and would be relatively unaffected by training designed to encourage these same processes. Consistent with this prediction, goal-oriented training had no significant impact on the transitions from PF (to either PE or SA). The different effects of goal-oriented training on transitions from SA to PE and from PF to PE represent a striking confirmation of our interpretation of previous results, involving live incidents, and of the view that goal-oriented training affected incident commander activity in the present experiments through changing the balance between reflective and reflexive processes. How goal-oriented training affects this balance cannot be determined on the basis of the results of Experiments 1-3, and will be a subject for future research. One possibility is that it increases the accessibility of goal-directed systems that subserve planful behavior, but would otherwise be overridden by more habitual, stimulusdriven processes (e.g., recognition priming; Klein, 1993; see also, Ajzen, 1991; Gore et al., 2015) or associative priming (e.g., Doya, 2008; Honey, 2000). The impact of changes in the balance between reflective and reflexive processes on failures to arrive at a decision (e.g., decision inertia; Alison et al., 2015) is another potential avenue for future research.

The finding that a relatively brief period of goal-oriented training had a marked impact on the nature of decision making is surprising given the nature of the participants, most of whom had many years of experience in their current role. The results of Experiments 1-3 show that training in the use of decision controls is an effective means of generating explicit planning in incident commanders that should provide the basis for more effective communication with their crews (cf. Endsley, 1995; Schmitt \& Klein, 1999). It should be acknowledged that we have no direct evidence that communication was improved, and nor do we know whether or not the observed changes in decision-making processes were linked to changes in the nature or effectiveness of the decisions that were generated. Further research will be needed to assess these issues. However, it certainly seems plausible to suppose that the changes in decision-making processes in Experiments 1-3 would provide the basis for more effective communication.

Before concluding this discussion it is worth reflecting on the utility of simulated exercises more generally. The downward trend in the number of operational incidents (e.g., Department for Com- munities and Local Government, 2014) means that incident commanders receive less operational field experience than was the case in the past. Simulated exercises-whether using computergenerated scenarios or traditional training ground exercises-are a widely used substitute. However, there are many differences between simulations and reality, such as the level of actual risk, uncertainty, and moral pressures. The degree to which they reflect real-life decisions is currently unexplored in relation to command. In Experiments 1-3, the same scenarios were used across a range of simulated environments, with differing degrees of realism (VR, fireground, and live burns). The patterns of decision making were remarkably similar across the three environments, and participants who received standard training behaved in a manner that was very similar to that observed at live incidents in a recent field study (Cohen-Hatton et al., 2015; see also, Klein et al., 1989; Rake \& Njå, 2009). Moreover, the impact of goal-oriented training was also consistent across the three environments. Taken together, this evidence suggests that an increase in the use of command-focused simulations, with a focus on risk-critical and difficult decisions, will prove to be a useful part of a wider strategy to replace the experience lost through the decline in operational incidents.

To summarize: The results of three experiments show that goal-oriented training affects decision-making processes in experienced incident commanders across a variety of simulated environments ranging from immersive VR through to live burns. These findings indicate that the goals and the anticipated consequences of different courses of action are appropriate targets for training interventions, which can change the balance between reflective and reflexive processes. Such changes in decision-making processes offer the potential to increase the effectiveness of communication between members of emergency fire crews and to improve safety.

\section{References}

Ajzen, I. (1991). The theory of planned behavior. Organizational Behavior and Human Decision Processes, 50, 179-211. http://dx.doi.org/10.1016/ 0749-5978(91)90020-T

Alison, L., Power, N., van den Heuvel, C., Humann, M., Palasinski, M., \& Crego, J. (2015). Decision inertia: Deciding between least worst outcomes in emergency responses to disasters. Journal of Occupational and Organizational Psychology, 88, 295-321. http://dx.doi.org/10.1111/joop .12108

Chief Fire and Rescue Advisor. (2008). Incident command, 3rd edition, fire and rescue manual, Vol. 2: Fire service operations. London: The Stationary Office.

Cohen-Hatton, S. R., Butler, P. C., \& Honey, R. C. (2015). An investigation of operational decision making in situ: Incident command in the UK fire and rescue service. Human Factors, 57, 793-804. http://dx.doi.org/ $10.1177 / 0018720815578266$

Department for Communities and Local Government. (2014). Fire statistics Great Britain April 2013-March 2014. Retrieved from https://www.gov.uk/ government/uploads/system/uploads/attachment_data/file/410287/ Fire_Statistics_Great_Britain_2013-14___PDF_Version_.pdf

Dewey, J. (1933). How we think: A restatement of the relation of reflective thinking to the educative process. Boston, MA: Heath.

Doya, K. (2008). Modulators of decision making. Nature Neuroscience, 11, 410-416. http://dx.doi.org/10.1038/nn2077

Endsley, M. R. (1995). Toward a theory of situation awareness in dynamic systems. Human Factors, 37, 32-64. http://dx.doi.org/10.1518/ 001872095779049543 
Endsley, M. R. (2015). Situation awareness misconceptions and misunderstandings. Journal of Cognitive Engineering and Decision Making, 9, 4-32. http://dx.doi.org/10.1177/1555343415572631

Gore, J., Flin, R., Stanton, N., \& Wong, B. L. W. (2015). Applications of naturalistic decision-making. Journal of Occupational and Organizational Psychology, 88, 223-230. http://dx.doi.org/10.1111/joop.12121

Honey, R. C. (2000). Associative priming in Pavlovian conditioning. Quarterly Journal of Experimental Psychology, 53, 1-23. http://dx.doi .org/10.1080/027249900392977

House, A., Power, N., \& Alison, L. (2014). A systematic review of the potential hurdles of interoperability to the emergency services in major incidents: Recommendations for solutions and alternatives. Cognition Technology \& Work, 16, 319-335. http://dx.doi.org/10.1007/s10111013-0259-6

Klein, G. (1993). A recognition-primed decision (RPD) model of rapid decision making. In G. Klein, J. Orasanu, R. Calderwood, \& C. Zsambok (Eds.), Decision making in action (pp. 138-147). Norwood, NJ: Ablex.

Klein, G. (1998). Sources of power: How people make decisions. Cambridge, MA: MIT Press.

Klein, G. A., Calderwood, R., \& MacGregor, D. (1989). Critical decision method for eliciting knowledge. Systems, Man and Cybernetics. IEEE Transactions on, 19, 462-472.

Klein, G., Snowden, D., \& Pin, C. L. (2010). Anticipatory thinking. In K. Mosier \& U. Fischer (Eds.), Informed by knowledge: Expert performance in complex situations (pp. 235-246). New York, New York: Psychology Press.

Lipshitz, R., \& Bar-Ilan, O. (1996). How problems are solved: Reconsidering the phase theorem. Organizational Behavior and Human Decision Processes, 65, 48-60. http://dx.doi.org/10.1006/obhd.1996.0004

McLennan, J., Omodei, M. M., Rich, D., \& Wearing, A. J. (1997). Helmet-mounted video: Applications for fire officer training and operations. Journal of the Fire Service College, 3, 67-74.
O'Connor, B. P. (1999). Simple and flexible SAS and SPSS programs for analyzing lag-sequential categorical data. Behavior Research Methods, Instruments, \& Computers, 31, 718-726. http://dx.doi.org/10.3758/ BF03200753

Rake, E. L., \& Njå, O. (2009). Perceptions and performances of experienced incident commanders. Journal of Risk Research, 12, 665-685. http://dx.doi.org/10.1080/13669870802604281

Roberts, R., Flin, R., \& Cleland, J. (2015). Staying in the zone: Offshore drillers' situation awareness. Human Factors, 57, 573-590. http://dx.doi org $/ 10.1177 / 0018720814562643$

Sackett, P. (1979). The lag sequential analysis of contingency and cyclicity in behavioural interactional research. In J. D. Osofsky (Ed.), Handbook of infant development (pp. 623-649). Chichester: Wiley and Sons.

Schmitt, J. F., \& Klein, G. (1999). How we plan. The Marine Corps Gazette, 83, 18-26.

Stanton, N. A., Salmon, P. M., \& Walker, G. H. (2015). Let the reader decide: A paradigm shift for situation awareness in sociotechnical systems. Journal of Cognitive Engineering and Decision Making, 9, 44-50. http://dx.doi.org/10.1177/1555343414552297

van den Heuvel, C., Alison, L., \& Crego, J. (2012). How uncertainty and accountability can derail strategic 'save life' decision in counterterrorism simulations: A descriptive model of choice deferral and omission bias. Journal of Behavioral Decision Making, 25, 165-187. http:// dx.doi.org/10.1002/bdm.723

van den Heuvel, C., Alison, L., \& Power, N. (2014). Coping with uncertainty: Police strategies for resilient decision-making and action implementation. Cognition, Technology \& Work, 16, 25-45. http://dx.doi.org/ 10.1007/s10111-012-0241-8

Received March 19, 2015

Revision received August 10, 2015

Accepted August 12, 2015

\section{ORDER FORM}

Start my 2016 subscription to the Journal of

Experimental Psychology: Applied ${ }^{\circledR}$ ISSN: 1076-898X

$\$ 64.00$ APA MEMBER/AFFILIATE

$\$ 145.00$ INDIVIDUAL NONMEMBER

$\$ 606.00$ INSTITUTION

Sales Tax: $5.75 \%$ in DC and 6\% in MD

TOTAL AMOUNT DUE

Subscription orders must be prepaid. Subscriptions are on a calendar year basis only. Allow 4-6 weeks for delivery of the first issue. Call for international subscription rates.

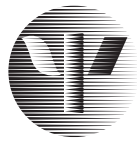

AMERICAN PSYCHOLOGICAL ASSOCIATION

\section{SEND THIS ORDER FORM TO}

American Psychological Association

Subscriptions

750 First Street, NE

Washington, DC 20002-4242

Call 800-374-2721 or 202-336-5600

Fax 202-336-5568 :TDD/TTY 202-336-6123

For subscription information,

e-mail:subscriptions@apa.org $\square$ Check enclosed (make payable to APA)

Charge my: $\square$ Visa $\square$ MasterCard $\square$ American Express

Cardholder Name

Card No. Exp.Date

\section{Signature (Required for Charge)}

\section{Billing Address}

Street

City State Zip

Daytime Phone

E-mail

Mail To

Name

Address

City State Zip 